\title{
Comparison of Safety and Efficacy Between Dabigatran and Rivaroxaban in Nonvalvular Atrial Fibrillation in Tertiary Level Hospital
}

\author{
MOHAMMAD HASIMUL AHASAN, MANZOOR MAHMOOD, DIPAL KRISHNA ADHIKARY, SYED ALI AHSAN, \\ CHAUDHURY MESHKAT AHMED, MD. ABU SALIM, KHURSHED AHMED, MD. RASUL AMIN, MD. FAKHRUL \\ ISLAM KHALED, CHAYAN KUMAR SINGHA, RASHEDUL ISLAM, SANJIDA ANSARI, SUMON KUMAR BISWAS, \\ RAJON KARNA, SAJAL KRISHNA BANERJEE
}

Department of Cardiology, Bangabandhu Sheikh Mujib Medical University (BSMMU), Dhaka

Address of Correspondence: Dr. Mohammad Hasimul Ahasan, Resident (Phase-B), Department of Cardiology, Bangabandhu Sheikh Mujib Medical University, Dhaka. E-mail-hasimulahasan786@gmail.com

\begin{abstract}
Background: Thromboembolism is a major complication of atrial fibrillation. Vitamin $K$ antagonist is the main oral anticoagulant which was used for prevention of thromboembolism in atrial fibrillation for many years. New oral anticoagulant drugs are emerging as alternatives to warfarin for the prevention of stroke in patients with non-valvular atrial fibrillation.

Objective: The aim of the study was to compare safety and efficacy of dabigatran and rivaroxaban for prevention of thromboembolism in tertiary level hospital

Methodology: This Randomized controlled trial study was conducted in the Department of Cardiology in Bangabandhu Sheikh Mujib Medical University, Shahbagh, Dhaka. Patients were divided into two groups, in group A 37 patients were given dabigatran $110 \mathrm{mg}$ twice daily and in group $B 37$ patients were given rivaroxaban $20 \mathrm{mg}$ daily for 6 months duration. Data was collected according to the pre designed semistructured data collection sheet. Statistical analyses were carried out by using the Statistical Package for Social Sciences (SPSS) version 23.0 for Windows Software.

Results: The mean CHADS2-VASC score (Risk of stroke) in rivaroxaban group and in dabigatran group was $3.95 \pm 1.37$ and $3.74 \pm 1.42$ respectively. There was no significant difference of CHADS2-VASC score between the two groups. Regarding outcome of 6th month follow up 2(5.4\%) patients were lost to follow up in dabigatran group and $3(8.1 \%)$ in rivaroxaban group. Comparaing effectiveness and safety study we found that ischemic stroke rate with rivaroxaban group was higher than dabigatran group although statistically not significant. We also found higher bleeding rate in rivaroxaban group than dabigatran group although statistically not significant.

Conclusion: Dabigatran is a safe and effective anticoagulant same as rivaroxaban for prevention of thromboembolism in the treatment of non valvular atrial fibrillation.
\end{abstract}

Key word: Thromboembolism, atrial fibrillation, dabigatran and rivaroxaban

University Heart Journal 2022; 18(1): 10-13

Introduction

Atrial fibrillation is the most common cardiac arrhythmia and associated with a fivefold increased risk of stroke. ${ }^{1}$ Several large trials have suggested that NOACs have similar or improved efficacy compared with warfarin and are more convenient and safer alternatives to warfarin. ${ }^{2}$ Warfarin effectively reduces the risk by $64 \%$ but required regular international normalized ratio testing and dose adjustment and has numerous interaction with other drugs and foods. ${ }^{3,4}$ The introduction of the non vitamin $\mathrm{k}$ antagonist oral anticoagulants (NOACS) has been a major advanced, as NOACS overcome some of these limitations and have demonstrated at least equivalent efficacy and safety in large phase III clinical trials. 5,6

Patients and clinicians now have choice between the available NOACS but have relatively little evidence to guide their decision making. No head to head trials of these NOACS exist. For dabigatran etexilate, observational studies have corroborated trial finding confirming that dabigatran provides non inferior stroke protection and similar or lower bleeding risk compared to warfarin. ${ }^{7,8}$ Findings from the Dresden NOACS registry suggest 
noninferior or lower major bleeding rates with rivaroxaban than with vitamin $\mathrm{K}$ antagonist. ${ }^{9}$

\section{Materials and Methods}

This Randomized controlled trial study was conducted in the Department of Cardiology in Bangabandhu Sheikh Mujib Medical University, Shahbagh, Dhaka. 74 patients of non-valvular atrial fibrillation included in this study who gave consent to be enrolled in this study. Patients were divided into two groups, in group A 37 patients were given dabigatran $110 \mathrm{mg}$ twice daily and in group B 37 patients were given rivaroxaban $20 \mathrm{mg}$ daily for 6 months duration. Data was collected according to the pre designed semi-structured data collection sheet. Statistical analyses were carried out by using the Statistical Package for Social Sciences (SPSS) version 23.0 for Windows Software.

\section{Results}

Majority patients belonged to age group 61-70 years in both groups. The mean age was found $59.92 \pm 10.13$ years in group A (Dabigatran) and 61.42 \pm 11.21 years in group $\mathrm{B}$ (Rivaroxaban). The mean age difference was not statistically significant between two groups (Table-I). Table II shows that hypertension, diabetes, previous stroke or TIA, peripheral vascular disease, congestive heart failure, previous myocardial infarction and CKD were not statistically significant as compared between two groups. Regarding CHADS2-VASC score (Risk of stroke) $\geq 4$ was more in Rivaroxaban group (45.9\%) than in Dabigatran group (35.1\%). The mean CHADS2- VASC score (Risk of stroke) in Rivaroxaban group and in Dabigatran group was $3.95 \pm 1.37$ and $3.74 \pm 1.42$ respectively. There was no significant difference of CHADS2- VASC score between the two groups (Table-III). In this study 2(5.4\%) patients were lost to follow up in dabigatran group and $3(8.1 \%)$ in rivaroxaban group. Comparaing effectiveness and safety study we found that ischemic stroke rate with rivaroxaban group is higher than dabigatran group although statistically not significant. This study also showed higher bleeding rate in rivaroxaban group than dabigatran group. Intracranial haemorrhage including haemorrhagic stroke, gestrointestinal bleeding was more in rivaroxaban group than dabigatran group. There was no significant difference between the two groups (Table-IV).

Table I

Distribution of the study patients by age $(n=74)$

\begin{tabular}{lcrlccc}
\hline Age group (years) & \multicolumn{2}{c}{ Group A $(\mathrm{n}=37)$} & & \multicolumn{2}{c}{ Group B $(\mathrm{n}=37)$} & P value \\
\cline { 2 - 3 } \cline { 5 - 6 } & $\mathrm{n}$ & $\%$ & & $\mathrm{n}$ & $\%$ & \\
\hline$\leq 40$ & 1 & 2.7 & & 2 & 5.4 & \\
$41-50$ & 3 & 8.1 & & 4 & 10.8 & \\
$51-60$ & 10 & 27.0 & & 8 & 21.6 & \\
$61-70$ & 14 & 37.8 & & 12 & 32.4 & \\
$>70$ & 9 & 24.3 & & 11 & 29.7 & $0.547 \mathrm{~ns}$ \\
Mean \pm SD & $9.92 \pm 10.13$ & & $61.42 \pm 11.21$ & \\
\hline
\end{tabular}

Group A- Dabigatran; Group B- Rivaroxaban ns=not significant; P value reached from unpaired t-test

Table-II

Distribution of the study patients by coexisting conditions $(n=74)$

\begin{tabular}{lccccc}
\hline Co-existing conditions & \multicolumn{2}{c}{ Group A $(\mathrm{n}=37)$} & \multicolumn{2}{c}{ Group B $(\mathrm{n}=37)$} & P value \\
\hline Hypertension & 27 & 73.0 & 28 & 75.7 & $0.790 \mathrm{~ns}$ \\
Diabetes & 14 & 37.8 & 20 & 54.1 & $0.161 \mathrm{~ns}$ \\
Previous stroke or TIA & 2 & 5.4 & 3 & 8.1 & $0.643 \mathrm{~ns}$ \\
Peripheral vascular disease & 3 & 8.1 & 3 & 8.1 & $1.000 \mathrm{~ns}$ \\
Congestive heart failure & 14 & 37.8 & 15 & 40.5 & $0.811 \mathrm{~ns}$ \\
Previous myocardial infarction & 16 & 43.2 & 17 & 45.9 & $0.815 \mathrm{~ns}$ \\
CKD & 2 & 5.4 & 1 & 2.7 & $0.555 \mathrm{~ns}$ \\
\hline
\end{tabular}

ns=not significant; $\mathrm{P}$ value reached from Chi square t-test 
Table-III

Distribution of the study patients by CHADS2-VASC score $(n=74)$

\begin{tabular}{lcccccc}
\hline CHADS2- VASCscore & \multicolumn{2}{c}{ Group A $(\mathrm{n}=37)$} & & \multicolumn{2}{c}{ Group B $(\mathrm{n}=37)$} & P Value \\
\cline { 2 - 3 } & $\mathrm{n}$ & $\%$ & & $\mathrm{n}$ & $\%$ & \\
\hline 2 & 10 & 27.0 & & 8 & 21.6 & \\
3 & 14 & 37.8 & & 12 & 32.4 & \\
$\geq 4$ & 13 & 35.1 & & 17 & 45.9 & \\
Mean \pm SD & $3.74 \pm 1.42$ & & \multicolumn{2}{c}{$3.95 \pm 1.37$} & $0.519 \mathrm{~ns}$ \\
\hline
\end{tabular}

ns=not significant; $\mathrm{P}$ value reached from unpaired t-test

Table IV

Distribution of the study patients by outcome at 6th month of follow up $(n=69)$

\begin{tabular}{lccccc}
\hline Outcome & Group A $\left(\mathrm{n}=35^{*}\right)$ & \multicolumn{2}{c}{ Group B $(\mathrm{n}=34 \#)$} & P Value \\
\hline Ischemic stroke & 0 & 0.0 & 1 & 2.9 & $0.306 \mathrm{~ns}$ \\
Haemorrhgic stroke & 0 & 0.0 & 1 & 2.9 & $0.306 \mathrm{~ns}$ \\
Non CNS systemic embolism & 0 & 0.0 & 0 & 0.0 & \\
-Major bleeding & 1 & 2.9 & 2 & 5.9 & $0.537 \mathrm{~ns}$ \\
Intra cranial bleeding & 0 & 0.0 & 1 & 2.9 & $0.306 \mathrm{~ns}$ \\
Extra cranial bleeding & 1 & 2.9 & 1 & 2.9 & $0.983 \mathrm{~ns}$ \\
Minor bleeding & 1 & 2.9 & 2 & 5.9 & $0.537 \mathrm{~ns}$ \\
All causes mortality & 1 & 2.9 & 2 & 5.9 & $0.537 \mathrm{~ns}$ \\
Myocardial infarction & 1 & 2.9 & 0 & 0.0 & $0.320 \mathrm{~ns}$ \\
Gastrointestinal bleeding Dyspepsia & 4 & 11.4 & 1 & 2.9 & $0.174 \mathrm{~ns}$ \\
Hospital admission & 2 & 5.7 & 3 & 8.1 & $0.618 \mathrm{~ns}$ \\
Blood transfusion & 1 & 2.9 & 1 & 2.9 & $0.983 \mathrm{~ns}$ \\
\hline
\end{tabular}

* In group A, 2 patients were lost of follow up period;

\# In group B, 3 patients were lost of follow up period. ns=not significant; $\mathrm{P}$ value reached from Chi square t-test

\section{Discussion}

This Randomized controlled trial was carried out in the department of Cardiology, University Cardiac Center, Bangabandu Sheikh Mujib Medical University, Dhaka from November 2019 to October 2020. A total of 74 patients were enrolled in this study. The main objective of the study was to determine efficacy and safety of dabigatran for prevention of thromboembolism in patient with nonvalvular atrial fibrillation in tertiary level hospital. All patients who were diagnosed as a case of nonvalvular atrial fibrillation, were selected for anticoagulation at the study place during the study period.

The study was conducted on patients with age range from 18 to 78 years with a mean age of $59.92 \pm 10.13$ years in dabigatran group and $61.42 \pm 11.21$ years in rivaroxaban group. Sodrudrin et al. also supported our observation where mean age of rivaroxaban group was $57.66 \pm 10.92$ years. ${ }^{10}$ Mean age was higher in rivaroxaban group than dabigatran group which is similar to study done by Mentha and Ansell. ${ }^{11}$ In the present study it was observed that majority patients were male in both groups that were $24(64.9 \%)$ in group A and 21(56.8\%) in group B. Male: female ratio was 1.8:1 in dabigatran group and 1.3:1 in rivaroxaban group. Noseworthy et al. reported 58.9\% male in dabigatran group and $59.7 \%$ male in rivaroxaban group. ${ }^{12}$ Similar findings were also observed in study findings, where majority patients were male. ${ }^{5}$

In my study the mean CHADS2-VASC score (Risk of stroke) in dabigatran group was $3.74 \pm 1.42$ and in rivaroxaban group was $3.95 \pm 1.37$. Rivaroxaban group shows higher CHADS2- VASC score (Risk of stroke) where $45.9 \%$ patients had score $\geq 4$ where $35.1 \%$ patients 
shows similar findings in dabigatran group. This high score in rivaroxaban group is due to higher presence of history of stroke, hypertension, congestive heart failure, Peripheral arterial disease. Mentha and Ansell also reported similar findings when compared RE-LY and ROCKET AF Trial, where rivaroxaban group had high CHADS2- VASC score. ${ }^{11}$ Comparing effectiveness and safety we found that ischemic stroke rate with rivaroxaban group is higher than dabigatran group although statistically not significant. ${ }^{11}$ Similar finding reported by Noseworthy et al. where they found that event rate was higher in rivaroxaban group than dabigatran group which was $1.12 \%$ and $1.03 \%$ respectively. ${ }^{12}$ But Bai et al. showed that risk of stroke was similar with rivaroxaban when compared with dabigatran (hazard ratio 1.02,95\% CI,0.91-1.13);13 In my study high CHADS2-VASC score may be the cause of increased ischemic stroke rate in rivaroxaban group. This study also shows higher bleeding rate in rivaroxaban group than dabigatran group. Major bleeding occur $5.9 \%$ patients in rivaroxaban group and $2.9 \%$ patients in dabigatran group. ${ }^{13}$ Patel et al. reported that $3.6 \%$ patients suffered from major bleeding in rivaroxaban group. ${ }^{5}$ Connolly et al. (2009) reported $2.7 \%$ patients suffered from major bleeding in dabigatran group. ${ }^{14}$ Lip et al. also found that ribaroxavan was associated with higher risk of major bleeding compared to dabigatran. In this study Intracranial hemorrhage (Hemorrhagic stroke) and gastrointestinal bleeding was more frequent in rivaroxaban group than dabigatran group. In this study rivaroxaban is associated with lower occurrence of Myocardial Infarction than dabigatran group. ${ }^{15}$ Grost-Ramsesun et al. ${ }^{16}$ and Mentha and Ansell reported the similar findings in their observation. Dyspepsia was more common in dabigatran group than rivaroxaban group. $11 \%$ people suffered from dyspepsia in dabigatran group in this study. ${ }^{16,11}$ Patel et al..$^{5}$ found that all cause mortality of rivaroxaban group was $4.5 \%$ and Connolly et al. ${ }^{14}$ found that all cause mortality of dabigatran group was $3.7 \%$. Comparisons of all cause mortality did not suggest superiority of any new agent versus another. High mortality may be due to high comorbidities in rivaroxaban group.

\section{Conclusion}

Dabigatran is a safe and effective anticoagulant same as rivaroxaban for prevention of thromboembolism in the treatment of non valvular atrial fibrillation.

\section{References}

1. Jones NR, Taylor CJ, Hobbs FR, Bowman L, Casadei B. Screening for atrial fibrillation: a call for evidence. European heart journal. 2020 Mar 7;41(10):1075-85.

2. Chan YH, See LC, Tu HT, Yeh YH, Chang SH, Wu LS, Lee HF, Wang CL, Kuo CF, Kuo CT. Efficacy and safety of apixaban, dabigatran, rivaroxaban, and warfarin in Asians with nonvalvular atrial fibrillation. Journal of the American Heart Association. 2018 Apr 5;7(8):e008150.

3. Hart RG, Pearce LA, Aguilar MI. Meta-analysis: antithrombotic therapy to prevent stroke in patients who have nonvalvular atrial fibrillation. Annals of internal medicine. 2007 Jun 19;146(12):85767.

4. Holbrook AM, Pereira JA, Labiris R, McDonald H, Douketis JD, Crowther M, Wells PS. Systematic overview of warfarin and its drug and food interactions. Archives of internal medicine. 2005 May 23;165(10):1095-106.

5. Patel MR, Mahaffey KW, Garg J, Pan G, Singer DE, Hacke W, Breithardt G, Halperin JL, Hankey GJ, Piccini JP, Becker RC. Rivaroxaban versus warfarin in nonvalvular atrial fibrillation. New England Journal of Medicine. 2011 Sep 8; 365(10):883-91.

6. Giugliano RP, Ruff CT, Braunwald E, Murphy SA, Wiviott SD, Halperin JL, Waldo AL, Ezekowitz MD, Weitz JI, Š pinar J, Ruzyllo W. Edoxaban versus warfarin in patients with atrial fibrillation. New England Journal of Medicine. 2013 Nov 28;369(22):2093-104.

7. Larsen TB, Rasmussen LH, Skjøth F, Due KM, Callréus T, Rosenzweig M, Lip GY. Efficacy and safety of dabigatran etexilate and warfarin in " real- world" patients with atrial fibrillation: a prospective nationwide cohort study. Journal of the American College of Cardiology. 2013 Jun 4;61(22):2264-73.

8. Graham DJ, Reichman ME, Wernecke M, Zhang R, Southworth MR, Levenson M, Sheu TC, Mott K, Goulding MR, Houstoun M, MaCurdy TE. Cardiovascular, bleeding, and mortality risks in elderly Medicare patients treated with dabigatran or warfarin for nonvalvular atrial fibrillation. Circulation. 2015 Jan 13;131(2):157-64.

9. Beyer-Westendorf J, Förster K, Pannach S, Ebertz F, Gelbricht V, Thieme C, Michalski F, Köhler C, Werth S, Sahin K, Tittl L. Rates, management, and outcome of rivaroxaban bleeding in daily care: results from the Dresden NOAC registry. Blood, The Journal of the American Society of Hematology. 2014 Aug 7;124(6):955-62.

10. Sodruddin G, Rahman MM, Habib SA, Chowdhury MT, Bashar A, Hoque MH, Chowdhury AW, Akter N, Hossain SM, Banerjee SK. Rivaroxaban versus Warfarin for Prevention of Thromboembolism in Bangladeshi Patients with Non-Valvular Atrial Fibrillation. University Heart Journal. 2020 Oct 11;16(2):99-105.

11. Mantha S, Ansell J. An indirect comparison of dabigatran, rivaroxaban and apixaban for atrial fibrillation. Thrombosis and haemostasis. 2012;108 (09):476-84.

12. Noseworthy PA, Yao X, Abraham NS, Sangaralingham LR, McBane RD, Shah ND. Direct comparison of dabigatran, rivaroxaban, and apixaban for effectiveness and safety in nonvalvular atrial fibrillation. Chest. 2016 Dec 1;150(6):1302-12.

13. Bai Y, Deng H, Shantsila A, Lip GY. Rivaroxaban versus dabigatran or warfarin in real-world studies of stroke prevention in atrial fibrillation: systematic review and meta-analysis. Stroke. 2017 Apr;48 (4):970-76.

14. Connolly SJ, Ezekowitz MD, Yusuf S, Eikelboom J, Oldgren J, Parekh A, Pogue J, Reilly PA, Themeles E, Varrone J, Wang S. Dabigatran versus warfarin in patients with atrial fibrillation. New England Journal of Medicine. 2009 Sep 17;361(12):1139-51.

15. Lip GY, Larsen TB, Skjøth F, Rasmussen LH. Indirect comparisons of new oral anticoagulant drugs for efficacy and safety when used for stroke prevention in atrial fibrillation. Journal of the American College of Cardiology. 2012 Aug 21;60(8): 738-46.

16. Gorst Rasmussen A, Lip GY, Bjerregaard Larsen T. Rivaroxaban versus warfarin and dabigatran in atrial fibrillation: comparative effectiveness and safety in Danish routine care. Pharmacoepidemiology and drug safety. 2016 Nov;25(11):1236-44. 